\title{
Bridging the Knowledge Gap in Collaborative Research-in Dialogues We Trust
}

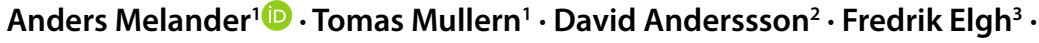 \\ Malin Löfving ${ }^{4}$
}

Accepted: 23 December 2021 / Published online: 5 January 2022

(C) The Author(s) 2022

\begin{abstract}
By building upon the prior work exploring the nature of practicing and knowing in collaborative research (CR), this article argues that focusing on how trust evolves in collaborative dialogue could enhance the learning potential in CR projects. Drawing from 42 workshops within a CR project, we analyze how dialogue and learning practices develop trust. We use the dialogical framework developed by Walton and Krabbe (1995) to identify and classify 107 dialogues. From our data, we identify three distinct dialogical patterns (educating, inquiring and practicing). These three dialogical patterns are related to four learning practices that are conceptualized as knowledge sharing, knowledge gapping, knowledge bettering and knowledge speculating. Combined, these dialogical patterns and learning practices develop collaborative trust in CR projects. We propose that these results represent an emerging conceptual language that addresses the development of trust in managing CR projects. This conceptual language can both improve managerial practice in the CR context and inspire future theory building.
\end{abstract}

\section{Introduction}

The management research has been criticized for its lack of relevance and its failure to obtain deeper insights into managerial practices (Rynes et al. 2001; Markides 2011). Such shortcomings have been described in terms of a gap between rigor and relevance (Beech et al. 2010; Chen et al. 2013), a lack of trust (Hemmert et al. 2014) and a lack of shared under-

Anders Melander

Anders.Melander@ju.se

1 Jönköping International Business School, Jönköping University, Box 1026, Jönköping, Sweden

2 Borand AB. Högalundsvägen 6, 56160 Tenhult, Jönköping, Sweden

3 School of Engineering, Jönköping University, Box 1026, Jönköping, Sweden

4 Träcentrum Nässjö, Framtidsvägen 1, 57135 Nässjö, Jönköping, Sweden 
standing (Scolari et al. 2015) between academics and practitioners. One response to this criticism has been an increase in research designs in which academics actively collaborate with stakeholders outside academia (Ankrah and Omar 2015). It is generally acknowledged that collaborative research can stimulate a much-needed conversation between researchers and practitioners (Cirella et al. 2012; Romme et al. 2015; Bartunek and McKenzie 2017) through which knowledge can be coproduced in ongoing dialogues (Marcos and Denyer 2012; Soulard and Lardon 2019).

An emerging stream of research highlights the dialogical aspects of collaborative research (cf. Beech et al. 2010; Chen et al. 2013), focusing on how individuals relate to each other through ongoing patterns of conversation (Heracleous et al. 2018). However, the importance of dialogue in collaborative research extends beyond the simple exchange of information that occurs in conversations between academics and practitioners (Pertuzé et al. 2010), as dialogue represents an important mechanism that can be used to address one of the most apparent obstacles in the collaborative research process, i.e., a lack of trust among collaborating parties (Dodgson 1996; Davenport et al. 1999; Hemmert et al. 2014). Trust is critical because the collaborating parties in a dialogue often represent different institutional logics (Astley and Zammuto 1992; Paterson et al. 2018); therefore, a trustful dialogue is essential for bridging logics and jointly producing knowledge (Chen et al. 2013; Van de Ven 2018). The CR literature also recognizes that the construction of trust is an important mitigator of institutional barriers (Santoro and Saparito 2003; Bruneel et al. 2010; Bstieler et al. 2017), and numerous studies have provided a deeper understanding of the role of trust in collaborative endeavors (Dodgson 1993; Oliver et al. 2019). Given the generic aim of CR to produce knowledge, it is also self-evident that trust is related to the knowledge accumulation process in CR projects (Rutten et al. 2016; Tootell et al. 2020). However, surprisingly, our knowledge regarding how trust is formed in learning-oriented contexts and especially in CR dialogues is limited (Hemmert et al. 2014; Beech et al. 2010).

The purpose of this paper is to further our knowledge of how trust evolves through dialogues within CR projects. We argue that the broader dialogic patterns that develop over the course of a CR project are related to specific learning situations, which are referred to as learning practices. In this paper, we uncover how trust develops in the interplay among such dialogue patterns and learning practices. In this context, trust is defined as a cyclical factor that serves as an important precondition for continuous dialogue and learning practices and their consequences. Therefore, we provide input to the literature that has called for more processual studies of trust formation over time, especially regarding the dynamics involved in trust formation within the dialogical setting (Korsgaard et al. 2002; Poppo 2013). We frame the results of this analysis in terms of an emerging conceptual language (Astley and Zammuto 1992).

The article begins with an introduction to the research on dialogue, trust and learning practices in the context of collaborative research. Then, we present the study background, methods, detailed research setting and organization of the analysis of dialogue and trust. After the data are presented, we theorize dialogue and trust within the CR context. We first identify the role of dialogue in collaborative research projects and classify it into three distinct patterns. Then, we identify four learning practices related to the dialogical patterns. Finally, we theorize the relationship among dialogical patterns, learning practices and collaborative trust. We conclude the article by reflecting on how the research on dialogue and trust can be further developed in the CR context. 


\section{Collaborative Research, Dialogue, Learning Practices and Trust}

The literature on organizational dialogue is diverse and covers a range of perspectives and approaches. Depending on the scope of the dialogue, we find two generic perspectives in the literature. The first adopts narrow conceptual boundaries. From this perspective, dialogue refers to distinct conversational patterns that adhere to generative objectives including mutual understanding and learning (Isaacs 2001; Raelin 2012). According to this perspective, dialogue is often organized and takes place in specific and prearranged settings. The second perspective takes more of a communicative view and considers the dialogical qualities among various conversational types, which include debates, quarrels, discussions, and argumentation (Barge and Little 2002; Pearce and Pearce 2004). Consequently, within this perspective, dialogue does not follow a prescribed design, can involve different stakeholders, and may have different purposes (Beech et al. 2010).

Collaborative research projects adhere to the first perspective because when joining such a collaboration, the parties are predisposed to jointly generate new knowledge in a specific setting (Van de Ven 2018). However, within this overarching learning orientation, over time, the process often combines dialogues that include conflicting goals and information asymmetries (Barge and Little 2002) and thereby incorporates insights from the second perspective. How such dialogical combinations unfold in collaborative research remains an open question: "...the criteria of idealized (hence generative) dialogue need not be met continuously. Instead, they need only be met often enough to generate resonances and ongoing ripples within a longitudinal research relationship" (Beech et al. 2010:1363f).

Following this conceptualization of dialogue in collaborative research, Gergen et al. (2004) review the dialogical actions that are crucial for achieving the overarching generative purpose of learning within the CR setting (Beech et al. 2010). These actions can be understood as the structural foundations of a generative dialogue and include the repetition of conversational topics, the affirmation of what has previously been said and constructive additions to further the dialogue. If these actions play out as intended, dialogue coherence emerges over time. However, a dialogue's coherence alone does not result in a learning outcome. If all parties echo each other's utterances, there will be no progress. Therefore, a dialogue must include knowledge differences to achieve a generative outcome (Høvring et al. 2018). Gergen noted, "In a more general sense, generative dialogue depends on the continuous generation of differences" (2004:7). An apparent knowledge difference is represented in the setup of the CR project, where the participating parties represent different knowledge bases (most often, practitioners and academics) (Marcos and Denyer 2012). We follow Tsoukas (2009) and argue that knowledge of how dialogical structures interplay with initial knowledge differences over time is undeveloped and in need of further theorizing. Following the purpose of this paper, to advance our knowledge regarding how trust evolves through dialogue within CR projects, we focus on how trust is formed within the context of CR dialogue.

Trust is a multidimensional construct that is studied in several disciplines. Even if we delimit our focus to trust within interorganizational relations, numerous frameworks have been suggested (Seppänen et al. 2007). One that is applied in the CR context (Dodgson 1996; Davenport et al. 1999), suggested by Sako (1992), includes three trust types: contractual trust, competence trust, and goodwill trust. Contractual trust is based on adherence to agreements and promises, competence-oriented trust is based on the competent performance 
of assigned roles, and goodwill trust is based on a belief in fairness and mutual commitment. When partners reach a level of goodwill trust, "trust must extend beyond that of expectations of partners to contribute what was contractually obliged of them. The level of trust in the relationship should also encompass unexpected and unsolicited suggestions for partners benefit..." (Dodgson 1993:83).

The relationship between trust and dialogue can be best described as dialectic. On the one hand, it can be argued that dialogue is the means by which trust evolves (Ciszek 2018; Yang et al. 2015). On the other hand, it can be argued that learning-oriented dialogue is difficult to accomplish unless an element of trust exists between the parties (McKnight et al. 1998). It would therefore be a mistake to reduce the relationship between the two concepts to a strictly causal one.

Although the importance of trust has been acknowledged, empirical studies investigating how trust is formed (Korsgaard et al. 2002) and the roles played by trust in dialogue and learning are lacking (Raelin 2012: Landrum et al. 2015; Oliver et al. 2019). When focusing on how trust is formed within CR dialogue, it must be recognized that CR dialogue addresses activities related to learning. Hence, it is essential to identify the learning practices (Hibbert et al. 2016) employed in dialogues if we aim to obtain an understanding of how trust evolves (Beech et al. 2010; Tootell et al. 2020). This contextual characteristic of CR directs our attention to how learning practices, which are defined as activities that occur to support learning (Hibbert et al. 2016), are related to trust. We can assume that the positive outcomes of such practices feed all three trust types suggested by Dodgson (1996) as they are expected to influence contractual trust (whereby parties learn that they must honor their agreements), competence trust (whereby parties learn that they must fulfill the roles assigned to them in the dialogue), and goodwill trust (whereby parties learn that they are to receive fair treatment in the dialogue) (Davenport et al. 1999; Ford 2013).

Learning practices related to trust can assume many forms and include the acquisition of "deep" knowledge through intensive focused search for the generation of purely new knowledge (Nonaka 1994). In a language-based analysis, Tsoukas (2009) postulates the following three learning practices from dialogue: conceptual combination, conceptual expansion and conceptual reframing. Additionally, when studying the role of interpretation in collaboration, Hibbert et al. (2016) identified the following three learning practices: exploring limitations, developing connections and developing shared interpretive horizons. We build upon these forerunners when conceptualizing three learning practices in the dialogical context. The first process occurs when the parties learn about the other parties' experiences and life world (Schutz and Luckmann 1973) within the dialogue. The outcome of such an exchange is a "dialogical understanding" (Tsoukas 2009:943) that is linked to increased predictability, hence constituting a platform for enforced contractual trust (Lewicki et al. 2006).

The second learning process occurs when the partners in the dialogue scrutinize each other's logical reasoning and, in this process, realize gaps in their own logic. Hence, selfreflection spurred in the dialogue causes the participants to gain awareness of their inherent knowledge as well as their knowledge gaps (Polanyi 1966; Nonaka 1994). This represents a "knowing-from-within" process (Cunliffe and Scaratti 2017:30). Finally, in the third process, the parties in the dialogue attempt to explore a new knowledge space as a form of applied imagination (Osborn 1953). This activity can be assisted by a structured procedure 
(cf. De Bono and Zimbalist 1970). Here, the dialogue becomes an arena for a more creative future-oriented learning process.

In summary, the dialogue between practitioners and researchers in collaborative research projects is generative and geared toward learning. In the literature review, we describe in some detail our knowledge regarding the nature of collaborative dialogue and how such dialogue and its resulting learning practices can be related to trust. In the following, we first present the empirical research and then further theorize on the relationship among dialog, learning practices and trust in collaborative research projects.

\section{Method}

This article began with a collaborative research project funded by the Swedish Governmental Agency for Innovation Systems (VINNOVA) between 2013 and 2016. The aim of the project was to adapt the Hoshin Kanri strategic management system (HK) to small - and medium-sized companies (SMEs) (HK is further described in Appendix A). The project was organized as a collaborative management research project (Cirella et al. 2012)) and included 14 companies, 64 managers and five researchers/trainers, all of whom participated in 101 workshops that lasted an average of $2.5 \mathrm{~h}$. All researchers/trainers took notes in the workshops. The notes were transcribed and analyzed in weekly project meetings (a total of 77 Skype meetings) attended by the entire research team. In total, the first phase resulted in fourteen case narratives that were each 5-48 pages long. Despite the same predefined approach, variation developed between the cases in terms of when and where different types of dialogue occurred.

A crucial principle in $\mathrm{HK}$ is systematic strategic conversation driven by the aim of obtaining company-wide consensus (Marksberry 2011, see appendix A). Ideas are to be communicated and discussed iteratively in fact-oriented conversation until well-anchored decisions are made. When analyzing the findings from the adoption processes, we gradually realized the importance of not only the internal strategic conversation within the company but also the role played by conversations between the research team and managers in the workshops. This reflection inspired us to focus on the dialogic process and to apply dialogue and trust theory as a lens to further our understanding of the collaborative research process.

The present paper is based on three of the case companies from the collaborative research project. The following selection criteria were used: (a) the three cases all included a substantial number of workshops (twelve or more), (b) the processes lasted 18 months or longer, (c) the processes offered wide learning opportunities because their characteristics and processes differed, and (d) the research teams' trust in the participating management teams was stable over time. The narratives of the three cases were rich (26-48 pages). In this way, a matching group of cases was created. The cases were anonymized and labeled Dock, Flex and Logg. In the following, we describe the more detailed research setting followed by the analytical framework. 


\section{The Collaborative Research Setting in This Project}

The research has identified important contextual aspects of collaborative research, which include a shared history among the participants (Thune 2007), the project's purpose (Shani et al. 2017), the spatial aspects (Ankrah and Omar 2015) and the project's participants and structure (Ankrah and Omar 2015). We use these contextual aspects to introduce the detailed research settings.

The shared history between the research team and the three participating companies was brief. In all cases, the same representative from the research team located potential participants based on one or two previous visits. Hence, two important sources of trust in this project, prior experience from collaborative research and a joint history, were low (Bstieler et al. 2017). The research team's (RT) information on the participating companies was mainly based on secondary sources.

A common objective was established when the CR project began: "The aim of this project is to establish an agile method for strategy work in SMEs, a method that enhances innovative growth." The participating companies signed a research contract acknowledging the research objective. However, we interpret the contractual trust in the project as low because the objective was broadly formulated, the contract was general in nature, and there was a lack of a joint history (Davenport et al. 1999).

The spatial aspects differed. In Dock and Logg, the workshops were organized at the companies; however, in Flex, for practical reasons, the workshops were organized at the nearby business school. As described in Table 1, the workshops in Flex and Logg lasted approximately three hours, but in Dock, they lasted five hours on average. The total number of workshop hours was somewhat equally distributed between Dock and Flex but was substantially lower in the Logg case. The intervals between workshops differed. In Flex and Logg, there were one and two long intervals between workshops. In Dock, the intervals were short at the beginning but longer in the end.

Table 1 The research setting

\begin{tabular}{llll}
\hline Component/case & Flex & Logg & Dock \\
\hline $\begin{array}{l}\text { Shared history } \\
\text { Objective }\end{array}$ & Brief & Brief & Brief \\
$\begin{array}{l}\text { Spatiality } \\
\text { Participation (months) }\end{array}$ & In line & In line & In line \\
$\quad$ Workshops & 31 & 24 & 20 \\
WS/Month & 18 & 12 & 12 \\
WS time (h) (average) & 0.6 & 0.5 & 0.6 \\
$\quad$ WS time in total (H & 3.3 & 2.9 & 5 \\
Participants & 59.4 & 34.8 & 60 \\
& CEO, TMT (4) & CEO, Owners (2), TMT & Owners (3 or \\
Employees & & $(6)$ & 2 ), TMT (6) \\
Industry & 90 & 76 & 20 \\
& Wood manufacturing & Wood manufacturing & Wood manu- \\
Turnover (MSEK) & & & facturing \\
Profitability (EBIT), average & 440 & 110 & 27 \\
Ownership & $5 \%$ & $5-10 \%$ & $5-10 \%$ \\
\hline
\end{tabular}


The number of participants varied among the three companies. In Dock, the three familyrelated owners participated initially, and the participant group was then extended twice to include the newly assigned top management team (TMT). Subsequently, two of the owners participated in all workshops. In Logg, the CEO participated in all workshops; in some, he was accompanied by the second owner, and in most, the entire TMT participated. In Flex, the entire TMT (four managers) participated in most workshops. Only in Logg (three workshops) and Flex (two workshops) were workshops attended by one company representative, the CEO. All such cases occurred at the beginning of the dialogic process.

We summarize the research setting in Table 1, which also provides company-specific facts.

\section{Data Analysis}

The broad field of dialogue studies, including work from disciplines such as political theory, political science, international relations, political history, education and communication studies (Raelin 2012), was reviewed in search of an analytical framework that was precise but also allowed for an abductive approach including various dialogical activities (Gergen 2004).

We chose to use the dialogical types introduced by Walton and Krabbe (1995) for the data analysis because this framework is well recognized; is broad in nature and includes a balance of several aims such as conflict solving, solving a common problem or reducing information asymmetry (ibid.). The framework also incorporated a productive dialogical structure, the need for which is discussed above, as underscored by Walton and Krabbe, who recognized the importance of commitment in dialogue. Although Walton and Krabbe do not explicitly discuss the role of trust in dialogue, their use of the commitment concept is clearly related to trust. That is, if the parties commit to a certain dialogical structure, this indicates a level of trust between the collaborating parties. This framework also represents a realistic labeling of dialogue and has, as the authors argue, "a normative bite" (Walton and Krabbe 1995:175). Furthermore, the framework has the potential for a more holistic analysis of dialogue by theorizing the mechanisms that determine how dialogues are linked and can change within the context of a single meeting. When coding our data, we made use

Table 2 Dialogical types used in coding

\begin{tabular}{|c|c|c|c|}
\hline $\begin{array}{l}\text { Nature of the } \\
\text { dialogue }\end{array}$ & Main type (and label) & Subtypes & \\
\hline Conflict & $\begin{array}{l}\text { Negotiation } \\
\text { (Goal: To make a deal) CO1 }\end{array}$ & & \\
\hline $\begin{array}{l}\text { Reduce } \\
\text { information } \\
\text { asymmetry }\end{array}$ & $\begin{array}{l}\text { Information seeking } \\
\text { (Goal: Spreading of knowledge), IA }\end{array}$ & $\begin{array}{l}\text { Expert consultation } \\
\text { (Goal: Layman accesses } \\
\text { knowledge), 1A1 }\end{array}$ & $\begin{array}{l}\text { Didactic dialogue } \\
\text { (Goal: Turn layman } \\
\text { into an expert), 1A2 }\end{array}$ \\
\hline \multirow[t]{2}{*}{$\begin{array}{l}\text { Common } \\
\text { goal }\end{array}$} & $\begin{array}{l}\text { Inquiry } \\
\text { (Goal: Together establish facts), } 1 \mathrm{CG}\end{array}$ & $\begin{array}{l}\text { Investigation } \\
\text { (Goal: Solve distinct } \\
\text { problem), 1CG1 }\end{array}$ & $\begin{array}{l}\text { Examination } \\
\text { (Goal: Find out level of } \\
\text { knowledge), 1CG2 }\end{array}$ \\
\hline & $\begin{array}{l}\text { Deliberation } \\
\text { (Goal: Find a way to act), } 2 \mathrm{CG}\end{array}$ & $\begin{array}{l}\text { Means-end discussion } \\
\text { (Goal: Choose one alter- } \\
\text { native), 2CG1 }\end{array}$ & $\begin{array}{l}\text { Discussion of ends } \\
\text { (Goal: Discuss possible } \\
\text { objectives), 2CG2 }\end{array}$ \\
\hline
\end{tabular}


of ten of the dialogical types and subtypes identified by Walton and Krabbe (1995). The ten types are introduced in Table 2.

Two authors of this article (one of whom participated in the data collection phase) coded the 26- to 48-page narratives independently and compared the outcomes. In doubtful cases, all researchers who participated in a specific workshop were consulted. Based on this initial coding, the authors iteratively authored shorter and more detailed dialogue-based reports on the three cases. Due to limitations of space, we include the entire Dock case in this article while we provide only brief vignettes for Logg and Flex. The description of the Dock case illustrates how the coding was performed in all cases. The coding of all dialogue in the workshops is summarized in Table 3 below.

The coding in Table 3 allowed for the identification of dialogical patterns within and between the cases. Two of the paper's authors individually conducted an ocular review, and the results were compared and tested among the three coauthors of the paper. In the analysis, we observed that all cases began with a first workshop dominated by an informationseeking dialogue (didactic). This reflected the plan for the workshop series: to spend the first workshop introducing the topic and set the stage for the project. Interestingly, as early as WS 2, the Dock case moved to a more elaborate dialogue structure with both deliberation and negotiation dialogues that explored alternatives in the deliberation dialogue and negotiated between alternative routes in the negotiation dialogue. In contrast, in subsequent workshops, both Logg and Flex continued to work only in the didactic dialogue type and initiated more elaborate dialogues at a later stage in the process.

In all three cases, there were patterns of dialogue that lasted 3-4 workshops or longer. In the Dock case, WSs 2-4 represent the first sequence of similar workshops, and in WSs 5-11, we identified a new sequence of workshops. We also identified the same dialogical patterns in Logg and Flex. In Logg, the order of the patterns was similar to that in Dock, although the timing differed. However, in Flex, the order was more mixed. In total, we identified nine sequences that were clustered in three dialogical patterns (see Table 3, below).

In the final analytical stage, we asked how these identified dialogical patterns were related to trust. Inspired by Dodgson's (1996) analyses of collaborative trust, we used the contractual, competence and goodwill types of trust as a starting point for this analysis and related these types of trust to the learning practices outlined in the theoretical framework. Hence, we analyzed the narratives of practices that addressed experiences and life worlds, the detection of knowledge gaps and explorations of new knowledge arenas. Based on critical incident theory (Flanagan 1954; Butterfield et al. 2005), we inductively identified incidents that expressed distinct representations of learning practices. Then, we theorized on the nature of the three identified types of dialogical patterns and learning practices. The results of this theorizing are reflected in the emerging conceptual language in this article.

In the following, we first introduce the empirical context with the extensive Dock case and the Logg and Flex vignettes. Then, we summarize both the analysis of individual dialogues and the identification of dialogue patterns in Table 3. Finally, we theorize on the relationship among dialogue patterns, learning practices and trust. 


\section{Results}

\section{The Dock Case}

Dock is a joinery that produces exterior doors. A member of the research team had been in contact with the company previously and knew that it had managerial challenges. After a phone call, he visited the company and discussed participation with the CEO. The decision to join was made quickly by the managing family owners (the $\mathrm{CEO}$, the marketing manager and the chairman of the board (their father)), and a formal contract recognizing the general objectives of the collaborative research project was soon signed. Two members of the research team participated in all workshops.

The focus of the first workshop was for the research team and the three owners to get to know each other. In the four-hour workshop, the owners were interviewed individually and in groups about the company's current situation and ambitions for the future. The dialogue in this workshop was classified as information-seeking and, more specifically, the didactic subtype (IA2) in Walton and Krabbe's framework. The owners took the role of informants who described and explained the company logic. The research team representatives took the role of layman. However, by asking exploring questions and seeking coherence, they communicated an understanding of the topics in question, that they were attentive to the presentation and that they were curious to know more.

In the second workshop, the research team introduced the Hoshin Kanri principles and more extensively introduced some analytical tools to the three owners. Here, the process again involved a didactic dialogue (IA2); however, the research team members were now the experts and the owners were the laymen. The owners asked exploratory questions and seemed to quickly realize how the problem-solving approach in HK could assist them. At the coffee break, a more informal dialogue took place in which the research team and the owners entered into a deliberating dialogue (2CG) (and, more specifically, a means-end dialogue, 2CG1) in which they discussed strategic challenges. The aim was to identify challenges to practicing the $\mathrm{HK}$ principles.

The research team questioned the first challenge suggested by the owners, and after a brief negotiation, the two parties decided to focus on a challenge that had been more of a "pebble in the shoe" for some time. Hence, a brief negotiation dialogue (CO1) was embedded within this means-end dialogue. In the last part of the workshop, the participants investigated the chosen challenge. This investigation dialogue (1CG1) included some didactic characteristics as the research team mainly asked the owners about facts related to the chosen challenge.

In workshop three, three research team members first recapitulated the process of the previous workshops. This was coded as an expert dialogue (IA1) in which one party, the expert, shared his or her knowledge with the layman. This was followed by an examination dialogue (1CG2) in which one of the owners presented the company achievements that had been attained since the last workshop. Within this dialogue, both the research team and the other owners asked control questions and constructed hypotheses on possible causalities. Hence, the examination dialogue soon slid into an investigation dialogue (1CG1).

As the investigation proceeded, the owners realized the need to include more employees in the process. These were employees who were part of both the problem (not following the established routine) and the solution (those who knew the most about the process). When 
the investigation reached the stage in which possible actions were listed, the dialogue transformed into an end-related dialogue (2CG2). At this stage, the research team introduced more analytical elements, ordering the following negotiation dialogue (CO1) where actions were prioritized. The prioritization tool was appreciated by the owners.

From the beginning, workshop four followed the same logic as workshop three. The research team recapitulated the previous workshop in an expert dialogue (IA1) followed by an examination dialogue (1CG2) in which the owners presented the achievements that had been attained since the previous workshop. Both of these dialogues were, to some degree, mixed with the following investigation dialogue (1CG1) as exploring questions were asked by all participants.

After some time, the following investigation dialogue (1CG1) was interrupted by one of the owners, who brought up the need to involve more employees in the process. It was apparent that the owners had discussed this topic before the workshop. Hence, there was a change in topic from the challenge of focus to the establishment of a top management team (TMT) within the investigation dialogue (1CG1). The investigation was even extended to include ways of involving all 20 employees in daily management activities. The owners quickly decided on how to proceed with both the TMT and the organization of daily management activities. Hence, there was no need for a negotiation dialogue.

In workshop five, three managers directed the new TMT to join the workshop. Initially, the workshop followed the same routine as the previous workshops, first with an expert dialogue (IA1) and then with an examination dialogue (1CG2). In the later dialogue, the owners declared that daily management had been successfully introduced in parts of the company. The research team then shadowed the first TMT meeting, which was an activity that was difficult to classify in dialogical terms. Afterward, all participants evaluated the meeting in a didactic dialogue (IA2). After the meeting (and lunch), the research team members, in more of an expert dialogue (IA1), shared their reflections on the TMT meeting with the CEO.

Workshop six followed the same initial dialogical structure as the previous workshops. Daily management and TMT meetings/structure were on track, but activities related to the specific strategic challenges were delayed. Therefore, the two parties decided in the workshop that the focus should be on exploring the next strategic challenge. Hence, the meeting proceeded with an investigation dialogue (1CG1). In this workshop and thereafter, only the two owning brothers participated in the workshops.

WS seven followed the same pattern as WS six. Workshop eight began with the CEO asking why the research team had come to visit. He answered this provocative question by saying that he felt that the process had entered an execution phase and that many responsibilities had been delegated within the company. The provocative question opened up a deliberation dialogue ( $2 \mathrm{CG}$ ) in which the overall objectives of the project were openly reviewed. When the workshop ended, the joint conclusion was that there was still a need for further workshops.

A new aspect in workshop seven and workshop eight was that the research team took time to individually coach the managers in problem solving. These activities are classified below as didactic dialogues, and they differed from previous didactic dialogues in that they involved only one company representative.

Workshops nine to eleven initially followed the routine established in workshop three and began with an expert dialogue (IA1) followed by an examination dialogue (1CG2). 
After the crucial discussion in workshop eight, the following workshops took an exploratory turn, either discussing the visionary objectives in an open manner (deliberation dialogue, $2 \mathrm{CG}$ ) or focusing on the identification of future challenges to address (investigation dialogue, 1CG1),

Finally, workshop twelve represented the end of the project. Here, the means-end dialogue focused on how the implementation of HK should proceed within the company. The owners were convinced that the project would continue and had prepared several activities.

\section{The Logg Case}

Logg produces kitchen components. The company is owned and managed by a married couple. The TMT, including both owners and four employed managers, meets once a month. The decision to join the project was made by the owners after two initial meetings with the research team representative. After these meetings, the research team met the TMT at workshop three, at which time all functional managers were interviewed individually. We classified these four interviews as one workshop (WS 4). After these interviews, the project came to a halt, and six months elapsed until the next workshop took place (WS 5). In the following WS, the focus was on investigating one specific strategic challenge. After the 6-month stoppage, the interval between the remaining workshops (WS 6-12) varied from two to 16 weeks. In most of these meetings, the entire TMT participated.

\section{The Flex Case}

Flex produces wood-based temporary buildings for the public sector. The CEO decided to join the research project as he sensed a need to improve strategic execution. Flex's management team consists of four functional managers. However, there are also more operational management teams at the two factories.

After an initial workshop was conducted with the CEO, the project began with managerial interviews. One workshop with the chair of the company board was followed by interviews with three members of the TMT. After this, the majority of workshops included all four members of the TMT. In the first eight months, only four workshops took place. The remaining 15 workshops were followed at regular 4-6-week intervals. The Flex case focused on three challenges in a sequential order. The second of these challenges dominated the process in WS 6-13.

\section{The Dialogues in the Three Cases}

In Table 3 below, we summarize the coding in the three cases according to workshops. Because Flex included six more workshops than the other two cases and several of those followed an identical outline (Flexes 7-9 and 10-12), we simplified the table somewhat. As discussed in the Methods section, Table 3 also includes the three identified dialogical patterns (named). The nature of these patterns is further discussed below. 


\section{Dialogical Patterns, Learning Practices and Trust}

After identifying the three dialogical patterns in Table 3, we discuss their characteristics and how these three patterns relate to learning practices and trust.

We named the first of the three identified dialogical patterns "educating." It is represented by the first sequence in the Logg and Flex cases. In the Dock case, this sequence appeared only in the first workshop and, therefore, did not represent a distinct pattern. As discussed above, this pattern was dominated by information-seeking dialogue, specifically of the didactic subtype, which is a dialogue in which one party in an iterative conversation educates another party and, as a result, the knowledge held by the different parties is shared. The second workshop in the Logg case represents a typical design of a workshop in the educating pattern. "The workshop with the leadership team started with a presentation of the project and Hoshin Kanri principles. Here, the company representatives asked some clarifying questions. This was followed by the CEO describing the current challenges in the company. The research team members frequently asked clarifying questions, and other TMT members added complementary information" (Research team notes, workshop 2, October 6, 2014).

The interactivity in these dialogues was driven by curiosity and an openness to understanding each other's different life worlds (Schutz and Luckmann 1973). In Barge and Little's words, the aim is to create a sense of unity (2002: 388) or dialogical understanding (Tsoukas 2009). We argue that the result of this dialogical pattern is predictability-based trust (Lewicki et al. 2006; Rousseau 1998). Based on Davenport et al. (1999), we argue that the trust emerging from these knowledge-sharing practices represents a basis for further trust-building activities (McNeish and Mann 2010).

- An educating dialogical pattern directed toward knowledge sharing practices..

The second type of dialogical pattern is represented by the first sequence in Dock, the second sequence in Logg and the third sequence in Flex. We call this dialogical pattern "inquiring" (after the dominating inquiry dialogue). Here, the collaborating parties ponder more detailed questions. These workshops are driven by the need to identify and solve distinct problems and knowledge differences (Gergen 2004). The core dialogues in these workshops are the examination and investigation dialogues, driven by a need to explore alternatives. These core dialogues facilitate identification of gaps in the existing knowledge spheres, which results in subsequent action. The actions that took place after the workshop were often characterized by practical investigations, experimentation, and external knowledge acquisition. Following March's (1991) terminology, we can label this inquiring pattern explorative, but it is an exploration within the boundaries of existing knowledge spheres in a type of "knowing-from-within" process (Cunliffe and Scaratti 2017:30). In this process of knowledge gapping, gaps are identified within the existing knowledge spheres. The following quote from the Dock case illustrates such gapping: "It's funny because the owners (company representatives) first say that they are in control, but when we start asking them more detailed questions, they soon realize that this is not the case. However, they also understand that they need to fill in these knowledge gaps to solve the challenge. So, after the workshop, they go home and investigate" (David, research team member, November 10, 2014).

These dialogues did not change any fundamental beliefs but rather encouraged a more open-minded and learning-oriented attitude within the dominating knowledge paradigm 


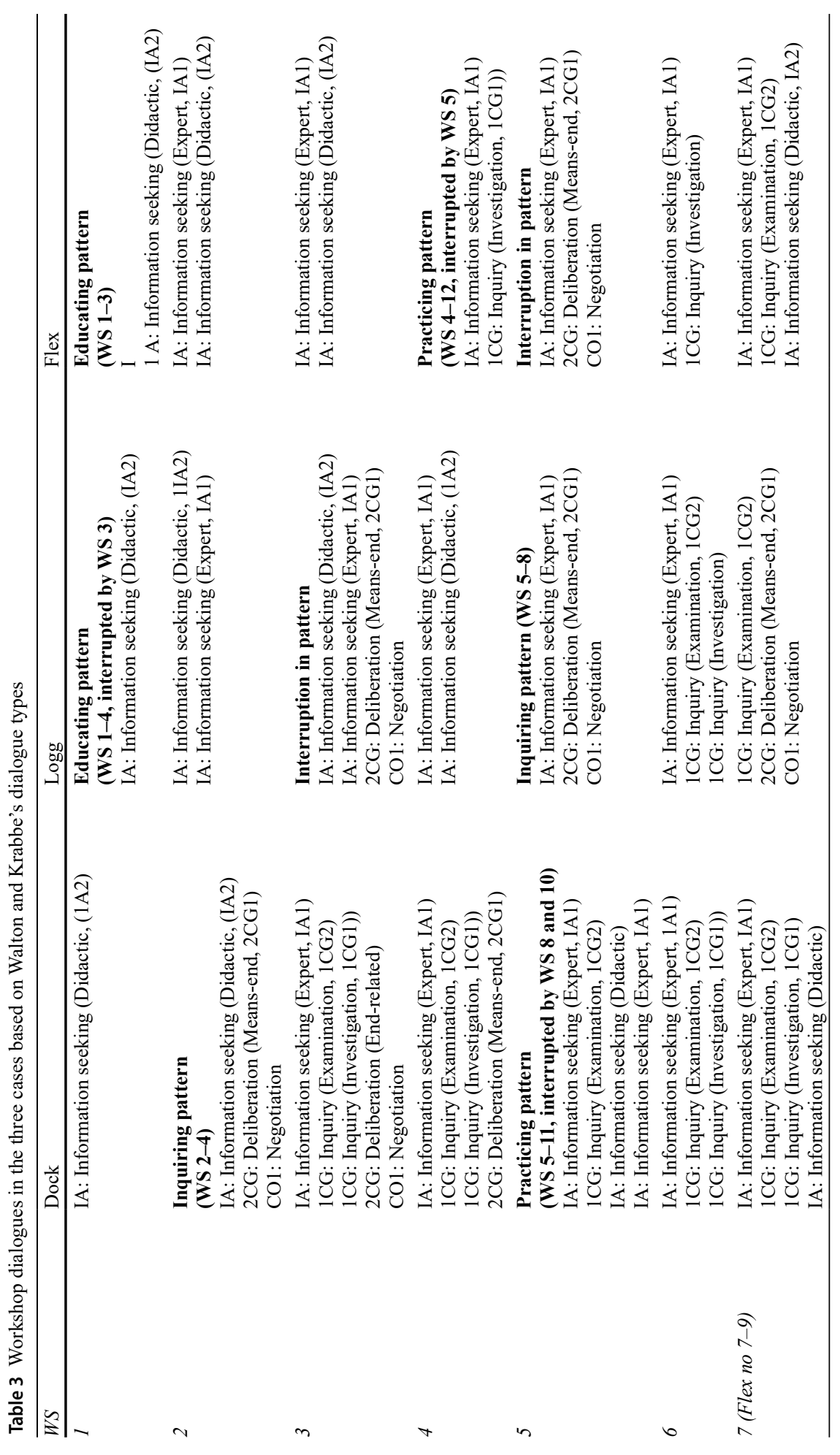




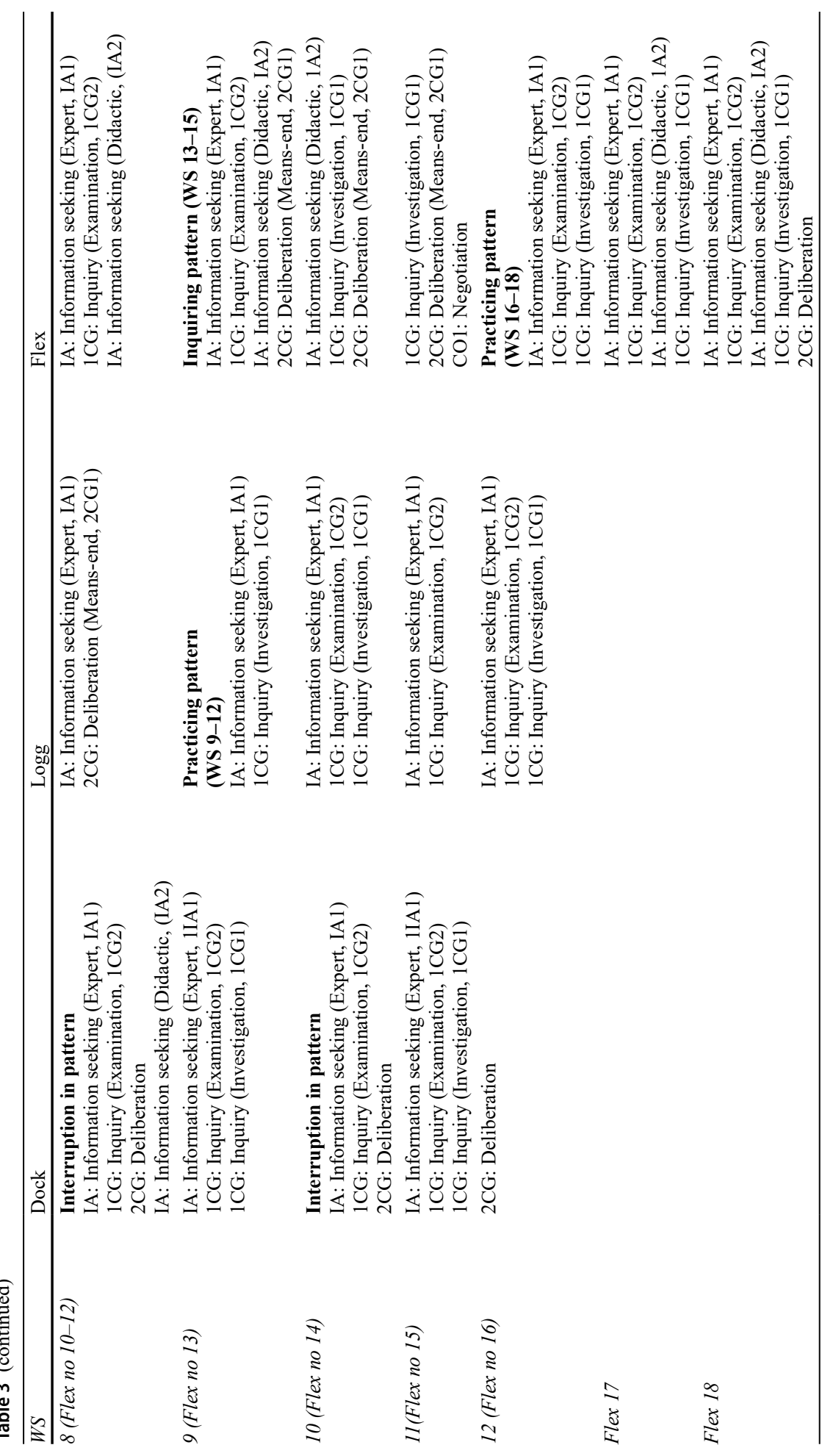


(Cranton 2003). We use the term inquiry when labeling this pattern to indicate that the focus is on qualifying existing knowledge. Gapping describes the realization of dominant lines of reasoning where the logic was questionable. However, although there was a focus on knowledge gapping, the performative outcomes were also essential for the development of trust in this pattern. Hence, the identified knowledge gaps were explicitly linked to improvements in the present conditions (Huxham 2003). The following notes from a WS in Dock exemplify the clear performative outcome of this dialogical pattern: "The WS began with the CEO reporting on the result of an organizational change discussed at the previous meeting. He was astonished. This simple change freed up one working day a week for him!" (Dock, research team notes January 28, 2015). Here, knowledge gapping, i.e., materializing apparent results, facilitated the development of competence-based trust between the parties (Cosner 2010).

- An inquiring dialogical pattern directed toward knowledge gapping practices..

The third type of dialogical pattern is represented by sequence two in Dock, sequence three in Logg and sequences two and four in Flex (see Table 3). We call this type of dialogical pattern "practicing." This pattern is also dominated by the inquiry type of dialogue. The difference is that the practicing process proceeds over a longer period and lacks the focus on immediate results. In Dock, the practicing pattern continued for eight workshops, and, in Flex, it continued for nine workshops. As a result, a rather stable processual dialogue structure was established within the workshops. The workshop began with an information-seeking and sharing dialogue (reporting of the present situation in the company) and continued with an inquiry (examination) dialogue (presenting activities conducted in the project since the last workshop). The consistent order of these dialogue types over several workshops signals high predictability, which relates to both contractual and goodwill trust (Lewicki et al. 2006). After this introduction, in most cases, the workshops proceeded with an inquiry dialogue in which operational issues were explored. These inquiry dialogues were resultsoriented and operational in character and signaled striving for an "action-directed practical agreement" (Walton and Krabbe 1995: 80). Such agreement was forward-oriented and based on a mutual goal. Overall, the practicing dialogical pattern was characterized by a clear focus on achieving results related to a defined topic, which is similar to the inquiry pattern. However, in the practicing pattern, the outcome was more distant; consequently, the process continued over longer periods and was more incremental in nature. In learning terms, we label these practices knowledge betterment. As a result of the longer planning horizon with several subprojects and experimentation, causal ambiguity (Lippman and Rumelt 1982) increased. This lack of a clear causality between activities and outcome was compensated by a joint understanding that all parties practiced their knowledge with a shared purpose, resulting in positive emotions (Poppo 2013:137). The established pattern of information sharing and inquiry (examination) dialogues at the beginning of each workshop enforced this belief in a shared purpose as they formed links to the past (and future) (Gergen et al. 2004; Poppo 2013). Therefore, in these dialogues, which initiated all the workshops in this pattern, a narrative of knowledge betterment was jointly constructed and shared to arrive at trust based on a shared responsibility for success or failure (Lawler 2001). As a result, the ultimate objective of the journey was not always a direct focus even if the conviction was that important results should materialize over time. To paraphrase March's (1991) concepts, 
knowledge betterment can be described as an exploitative execution within an explorative framing. Knowledge betterment is a process that develops competence-based trust.

- A practicing dialogical pattern directed toward knowledge betterment practices..

If we compare the three cases, Logg represents a clear overall logic in which the educating, inquiry and practicing dialogical patterns follow one another in sequential order. In Dock, there was only one educating workshop, but the inquiry and practicing sequences followed sequentially thereafter. However, Flex was an exception to this logic. In Flex, the practicing pattern followed the educating pattern; thus, there was no inquiry pattern in between. Moreover, the practicing pattern appeared twice. The first time, it lasted for eight workshops; after an interruption by the inquiry pattern in three workshops, the practicing pattern continued for another three workshops.

These changes from the practicing to the inquiry dialogical patterns and back were initiated in the 13th workshop, where at the end of the workshop, a member of the research team suggested a possible change of focus. The company CEO accepted the suggestion, and a deliberation dialogue in which new alternatives were briefly explored ended the workshop. In the following two workshops (14-15), a new, more promising focus gradually took over. These three workshops all followed the inquiry pattern of identifying and solving knowledge gaps within the new challenge. The immediate and promising results of these workshops increased engagement, and from WS 16, the practicing pattern reappeared.

This pattern illustrates the vulnerability of mutual trust emerging in the practicing pattern because the core of knowledge betterment is a joint conviction that the process ultimately should produce material results. If this belief in future gains is questioned, the established trust quickly fades. The Flex case illustrates this. The suggestion from a research team member to change focus in WS 13 was founded on a belief that the present challenge represented a dead end and that no tangible results would be reached. Hence, when the established trust was at stake, this triggered a successful change in the established dialogical pattern.

However, there were several other occasions during which the practicing pattern included a notable deliberation dialogue such as in the Dock case (WS 8, 10, and 12) and Flex case (WS 18). Upon closer examination of our data, we find that these deliberation dialogues were special and did not represent the operational discussion about specific means-ends (one of the subtypes) that appeared in the inquiry sequences. Here, the deliberation dialogue was more concerned with the exploration of the future (discussion of ends) and involved what Walton and Krabbe (1995:74) describe as "guesswork and speculations about plausible occurrences that might happen." In other words, a new knowledge space is explored (Osborn 1953). We illustrate with WS 8 in the Dock case, in which the CEO frankly asked the research team why they came to visit when they entered the company. This provocative question ended with a dialogue about the more distant future that can be labeled philosophical in nature. In this dialogue, among other topics, the company representatives (the CEO and his brother) reflected on their personal plans to expand into new businesses.

This finding indicates that we can theorize a fourth type of learning process that is liberating and visionary. In Gergen et al.'s (2004:41) terminology, this process exemplifies dialogues that "create new spaces of meaning." We use the word "theorize" as this type of deliberating dialogue only appeared in some instances within the practicing pattern. We label the learning process that occurred here knowledge speculation. Using this term, we address the gaming aspect of this process. This aspect is crucial because we propose that 
the word "speculation" has two meanings here. Speculation not only involves the action of envisioning possibilities for the future but also indicates that existing trust is at stake when speculation is initiated. It is not possible to know whether a collaborative partner is on the same wavelength at the beginning of speculation. If that is not the case, the dialogue can break down, and previously accumulated trust fades away. On the other hand, if the initiative is successful, the gains in terms of trust expansion can be substantial. We obviously assume that a clear link exists between this knowledge speculation process and the concept of goodwill trust as this sequence encompasses rather unexpected and unsolicited suggestions related to joint futuring (Dodgson 1993).

- A practicing dialogical pattern directed toward knowledge speculation practices..

To summarize, by examining the linkages between dialogues within the workshops, we identify combinations of dialogical types that go well together such as expert+examination dialogues, examination+investigation dialogues and deliberation+negotiation dialogues. At a more aggregated level, including several workshops, we identify nine dialogue sequences. These sequences can be ordered into three dialogical patterns (educating, inquiry and practicing). Then, we theorize on how these patterns are related to learning practices in collaborative research projects. Here, we note a dominance of knowledge sharing practices in the educating pattern and knowledge gapping practices in the inquiry pattern. In the practicing pattern, knowledge betterment practices dominate, but within this pattern, we also identified knowledge speculative practices. Finally, we link the identified dialogical patterns and learning practices to three types of collaborative trust, i.e., contractual trust, competence trust and goodwill trust.

We summarize the theorizing we have done thus far in Fig. 1 below.

\section{Dialogue and Trust in Collaborative Research-A Concluding Discussion}

In this article, we argue that dialogues and related learning practices in a CR project constitute a platform for trust to develop between collaborating parties (Cunliffe and Scaratti 2017). Therefore, in this paper, we analyzed how learning practices evolve within dialogical patterns in a CR project.

We frame the result of this analysis in terms of an emerging conceptual language (see Fig. 1). Astley and Zammuto (1992) suggest that the construction of a conceptual language shared by academics and practitioners can bridge their differing knowledge interests while shaping perceptions and enhancing problem-solving capabilities. In this paper, we follow

Fig. 1 Emerging conceptual language

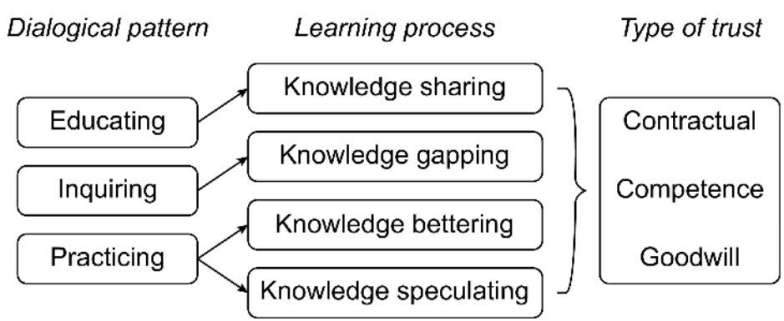


this idea, but we ultimately aim for a conceptual language that focuses on the CR process. We hope that this language can address barriers to successful CR management in the future (Ankrah and Omar 2015).

In this conceptual language, we propose that dialogues are at the core of the CR process and suggest that dialogue patterns are relevant for our understanding of how CR projects evolve. We identify and label three dialogical patterns (educating, inquiry and practicing). Furthermore, we relate these patterns to learning practices and identify four distinct outcomes (knowledge sharing, knowledge gapping, knowledge betterment and knowledge speculating), where knowledge betterment and speculating both emerged in the practicing pattern. We argue that these patterns and learning practices are all related to the construction and maintenance of collaborative trust. However, at this time, we are unable to propose a direct relationship. Overall, we view this focus on dialogue, learning practices and trust, which resulted in the suggestive concepts, as a step toward a conceptual language addressing the CR process.

This emerging language contributes to the CR research on two levels. First, we argue that the approach we take in this paper emphasizes aspects of CR that offer prospects for the future. The CR research has previously acknowledged the importance of bridging participating parties' interest in the collaborative process (Rynes et al. 2001). However, there are few examples of empirical studies that make use of dialogical research when addressing this issue (Beech et al. 2010; Kieser and Leiner 2012).

Following the application of dialogue theories on CR processes, the role of trust has emerged as central (von Brocke and Lippe 2015), and given the nature of CR, it is obvious that trust in this context is related to learning (Davenport 1999). Identifying learning-related practices directed toward dialogical patterns enhances our understanding of the relationship between dialogue and trust building. Therefore, in conclusion, we argue that the approach adopted in this paper, where literature from the fields of dialogue, learning and trust is combined to enhance our understanding of the CR process, offers promise for the future.

Second, our results, expressed as an emerging conceptual language, not only address the $\mathrm{CR}$ process but also contribute to the research on dialogue and trust. Both of these research fields can be described as vast, and we were unable to review all prospective contributions when authoring this paper. However, in our limited review, we detected only a few attempts to address the dynamic aspects that are at the center of this paper (cf. Cunliffe and Scaratti 2017; Sharma and Bansal 2020). We identified few studies that explicitly focused on the relationship between dialogical types (cf. Finkelberg 2018; Walton and Krabbe 1995), and we detected no studies aiming to understand how different types of dialogue combine and possibly form bundles, which we describe in this paper as dialogical patterns. When constructing an emerging conceptual language, we suggest three such patterns (educating, inquiry and practicing).

Similarly, we propose that the construction of dialogue-related trust is vital for our understanding of how CR projects develop (Bstieler et al. 2017), and this relationship can be better understood if we recognize learning practices. We identify the following four trustrelated learning practices: knowledge sharing, gapping, practicing and speculation.

We describe these results as an emerging conceptual language to emphasize that we do not regard the results of this research as final. The proposed concepts represent an initial attempt to describe the relationship among dialogue, learning and trust. We hope that our 
contribution will be followed by further research that allows us to better understand the inherent nature of the collaborative research process.

\section{Implications for the Management of Collaborative Research}

This article focuses on research projects that are practiced by researchers and practitioners in collaboration. Therefore, the results should be of practical use for managers and researchers who participate in and/or manage CR.

When considering engagement in CR activity, our advice is to carefully examine the setup of the CR arrangement from the dialogical, learning and trust perspectives. We strongly advocate that the element of trust that commonly initiates the dialogue between managers and practitioners in CR projects should also nurture ongoing dialogue between the parties. Consequently, an emphasis on learning practices in the dialogical patterns is essential for CR projects. Here, there should be room for diversity in learning practices. Knowledge sharing practices are social in character, knowledge gapping is performative in nature and long-term-oriented knowledge practices and speculation widen the perspective. These practices should all be addressed.

On a micromanagement level, the conceptualization of dialogue and trust outlined in this article provides a more detailed understanding of the CR process. This enriched understanding could lead to dialogue-planning activities that leverage the trust-building dynamics in CR projects (Vangen and Huxham 2003). For instance, when planning project activities, traditional agenda items could be related to specific dialogue types, requested learning practices and trust-building.

\section{Future Research}

In this paper, we have partially entered a new field in the CR research by exploring the potential of dialogue and trust. This process was generative but also frustrating as we identified several limitations in our research. To open avenues for future research on CR, trust and dialogue, we outline some of these limitations below.

The empirical data in the project represent a two-way restriction. The data, which were collected for another purpose, prevented the microanalysis of dialogues. Given this limitation, we look forward to future studies based on a processual analysis of detailed dialogue data originating from $\mathrm{CR}$ projects. To enhance the analysis of such dialogues, we selected three cases in which the research teams' trust in the management teams was stable over time (see selection criteria d), and the focus was thus on how the management teams' trust influenced the dialogical patterns. Obviously, this choice affected the dynamics of the studied dialogues and to some extent limited our contribution. In future studies, we see an interesting development where studies of collaborative research can be made in a more controlled format by studying several parties' changes in trust.

It is common in the dialogical research that a dialogue can involve several stakeholders (Beech et al. 2010). However, in our cases, some participants (mainly the CEO) participated in all company workshops, but other participants' involvement varied over time (see Table 1). In our analysis, we cannot detect any impact on the dialogical pattern from these 
changes; however, in the future, more controlled studies of dialogue, learning and trust can be conducted, in which it would be beneficial to control participation over time.

The data analyzed here also originate from a specific empirical context that includes managers with no previous experience with CR projects in small-and medium-sized manufacturing companies in Sweden. Although we believe that the proposed conceptual language should be validated by adoption, we encourage future studies focusing on both how the dialogue process unfolds in other collaborative research contexts, such as large, experienced and/or research-intensive companies and public organizations, and how learning practices can vary with dialogical patterns.

Finally, although the process outlined in this paper (see Fig. 1) provides a sequential impression, it is important to stress that with the present data, we are unable to predict causalities among dialogical patterns, learning practices and trust. Following Vanneste et al. (2014) and some of our empirical results (see especially the Flex case), it also seems that the trust that evolves from dialogue processes is vulnerable and may regress over time (cf. Korsgaard et al., 2002). Our preliminary conclusion is that the appearance and domination of different dialogues and learning practices in the CR process are empirically decided, but this conclusion is obviously open for discussion in future research.

\section{Appendix A}

The Hoshin Kanri (HK) strategic management system fosters ongoing and focused learning in organization-wide strategic conversations (Marksberry 2011). Overcoming communicative gaps, the process should increase employees' control over their work, resulting in higher satisfaction and productivity (Kondo 1998). Furthermore, the nature of HK invigorates managers to develop focused ambitions and an engaging coaching-oriented leadership style. As Nicholas (2016, p.8) concludes, "The HK process seems [to be] the embodiment of senior management involving."

Ideally, HK should first be implemented at the top management level and then deployed in the organization (cf. Tennant and Roberts 2001). The goal is for complete strategic inclusion (Kondo 1998; Jolayemi 2008). In a review of HK implementation where 23 vital aspects are identified (Giordani da Silverira et al. (2017), it is concluded that the primary focus should be on consistently applying a learning-oriented methodology (Cf Melander et al. 2016).

Funding Open access funding provided by Jönköping University.

Data Availability Statements The data in this article derives from research project financed by Vinnova [2013-02483] and consist of transcribed notes from 101 workshops. From these notes 26-48 page narratives were constructed. The data is not publicly available due to confidentiality agreements. Anonymized extracts covering the companies analyzed in this article can be made available from the corresponding author on reasonable request.

Declaration of Conflicting Interest This article is a part of a collaborative research project funded by a research grant from the Swedish Governmental Agency for Innovation Systems (VINNOVA) between 2013 and 2016. The aim of the project was to adapt the Hoshin Kanri strategic management system (HK) to small-and medium-sized companies (SMEs) (HK is further described in the article). The project was organized as a collaborative management research project with a research team of five and 64 representatives from 14 companies. The purpose of the project was approved by all parties ("The aim of this project is to 
establish an agile method for strategy work in SMEs, a method that enhances innovative growth.") and the research team regularly on an aggregated level reported the level of activity in the project to the financer. The final reporting of the project, in terms of a handbook and several research articles, is approved by the financer without any remarks. We hereby declare that there to our knowledge existed no conflict of interest in the above-mentioned research project.

Open Access This article is licensed under a Creative Commons Attribution 4.0 International License, which permits use, sharing, adaptation, distribution and reproduction in any medium or format, as long as you give appropriate credit to the original author(s) and the source, provide a link to the Creative Commons licence, and indicate if changes were made. The images or other third party material in this article are included in the article's Creative Commons licence, unless indicated otherwise in a credit line to the material. If material is not included in the article's Creative Commons licence and your intended use is not permitted by statutory regulation or exceeds the permitted use, you will need to obtain permission directly from the copyright holder. To view a copy of this licence, visit http://creativecommons.org/licenses/by/4.0/.

\section{References}

Ankrah S, Omar AT (2015) Universities-industry collaboration: A systematic review. Scand J Manag 31(3):387-408

Astley WG, Zammuto RF (1992) Organization science, managers, and language games. Organ Sci 3(4):443-460

Barge JK, Little M (2002) Dialogical wisdom, communicative practice, and organizational life. Commun Theory 12(4):375-397

Bartunek JM, McKenzie J (2017) Reviewing the state of academic practitioner relationships. In: Bartunek JM, McKenzie J (eds) Academic-Practitioner Relationships. Developments, complexities and opportunities. Taylor \& Francis, pp 1-10

Beech N, MacIntosh R, MacLean D (2010) Dialogues between academics and practitioners: The role of generative dialogic encounters. Organ Stud 31(9-10):1341-1367

Bruneel J, d'Este P, Salter A (2010) Investigating the factors that diminish the barriers to university-industry collaboration. Res Policy 39(7):858-868

Bstieler L, Hemmert M, Barczak G (2017) The changing bases of mutual trust formation in inter-organizational relationships: A dyadic study of university-industry research collaborations. J Bus Res 74:47-54

Butterfield LD, Borgen WA, Amundson NE, Maglio AST (2005) "Fifty years of the critical incident technique: 1954-2004 and beyond". Qual Res 15(4):475-497

Chen CY, Wu YCJ, Wu WH (2013) A sustainable collaborative research dialogue between practitioners and academics. Manag Decis 51(3):566-593

Cirella S, Guerci M, Shani AR (2012) A process model of collaborative management research: The study of collective creativity in the luxury industry. Syst Pract Action Res 25(3):281-300

Ciszek E, Logan N (2018) Challenging the dialogic promise: How Ben \& Jerry's support for Black Lives Matter fosters dissensus on social media. J Public Relat Res 30(3):115-127

Cosner S (2010) Drawing on a knowledge-based trust perspective to examine and conceptualize withinschool trust development by principals. J Sch Leadersh 20:117-144

Cranton P, Roy M (2003) When the bottom falls out of the bucket: Toward a holistic perspective on transformative learning. J Transform Educ 1(2):86-98

Cunliffe AL, Scaratti G (2017) Embedding impact in engaged research: Developing socially useful knowledge through dialogical sensemaking. Br J Manag 28(1):29-44

De Bono E, Zimbalist E (1970) Lateral thinking. Penguin, London, pp 1-32

Davenport S, Davies J, Grimes C (1999) Collaborative research programmes: building trust from difference. Technovation 19(1):31-40

Dodgson M (1993) Learning, Trust, and Technological Collaboration. Hum Relat 46(1):77-95

Dodgson M (1996) Learning, trust and inter-firm technological linkages: some theoretical associations. Technological Collaboration, the Dynamics of Cooperation in Industrial Innovation, Edward Elgar

Flanagan J (1954)) “The Critical Incident Technique. ”. Psychol Bull 51:327-358

Finkelberg M (2018) The Explicit and the Implicit Narrator Combined: Mixed Dialogues. In: The Gatekeeper: Narrative Voice in Plato's Dialogues. Brill, pp 76-102

Ford D (2013) Trust and knowledge management: the seeds of success. In: Holsapple CW (ed) Handbook on Knowledge Management. Vol 1. Knowledge Matters. Springer-Verlag, Berlin, pp 553-575 
Gergen KJ, Gergen MM, Barrett FJ (2004) Dialogue: Life and death of the organization. In: Grant D, Hardy DC, Oswick C, Putnam L (eds) The Sage handbook of organizational discourse. Sage. pp. 3S59, London, pp 39-59

Giordani da Silveira W, de Lima E, Gouvea da Costa SE, Deschamps F (2017) Guidelines for Hoshin Kanri implementation: development and discussion. Prod Plan Control 28(10):843-859

Hemmert M, Bstieler L, Okamuro H (2014) Bridging the cultural divide: Trust formation in universityindustry research collaborations in the US, Japan, and South Korea. Technovation 34(10):605-616

Heracleous L, Gößwein J, Beaudette P (2018) Open strategy-making at the Wikimedia foundation: a dialogic perspective. J Appl Behav Sci 54(1):5-35

Hibbert P, Siedlok F, Beech N (2016)) "The role of interpretation in learning practices in the context of collaboration.". Acad Manag Learn Educ 15(1):26-44

Huxham C (2003) Theorizing collaboration practice. Public Manag Rev 5(3):401-423

Høvring CM, Andersen SE, Nielsen AE (2018) Discursive tensions in CSR multi-stakeholder dialogue: A Foucauldian perspective. J Bus Ethics 152(3):627-645

Isaacs WN (2001) Toward an action theory of dialogue. Int J Public Adm 24(7-8):709-748

Jolayemi JK (2008) Hoshin kanri and hoshin process: A review and literature survey. Total Qual Manag 19(3):295-320

Kieser A, Leiner L (2012) Collaborate with practitioners: But beware of collaborative research. J Manag Inq 21(1):14-28

Kondo Y (1998) Hoshin kanr-a participative way of quality management in Japan. The TQM Magazine $10(6): 425-430$

Korsgaard MA, Brodt SE, Whitener EM (2002) Trust in the face of conflict: The role of managerial trustworthy behavior and organizational context. J Appl Psychol 87(2):312-319

Landrum AR, Eaves BS Jr, Shafto P (2015) Learning to trust and trusting to learn: A theoretical framework. Trends Cogn Sci 19(3):109-111

Lawler EJ (2001) An affect theory of social exchange. Am J Sociol 107(2):321-352

Lewicki RJ, Tomlinson EC, Gillespie N (2006) Models of interpersonal trust development: Theoretical approaches, empirical evidence, and future directions. J Manag 32(6):991-1022

Lippman SA, Rumelt RP (1982) Uncertain imitability: An analysis of interfirm differences in efficiency under competition. Bell j econ 418-438

McNeish J, Mann IJS (2010) Knowledge sharing and trust in organizations. IUP J Knowl Manag 8(1/2): 18

Marcos J, Denyer D (2012) Crossing the sea from they to we? The unfolding of knowing and practising in collaborative research. Manag Learn 43(4):443-459

March JG (1991) Exploration and exploitation in organizational learning. Organ Sci 2(1):71-87

Markides C (2011) Crossing the chasm: How to convert relevant research into managerially useful research. J Appl Behav Sci 47(1):121-134

Marksberry PW (2011) The theory behind hoshin: a quantitative investigation of Toyota's strategic planning process. Int J Bus Innov Res 5(3):347-370

Mayer RC, Davis JH, Schoorman FD (1995) An integrative model of organizational trust. Acad Manage Rev 20(3):709-734

McKnight DH, Cummings L, Chervany NL (1998) Initial trust formation in new organizational relationships. Acad Manage Rev 23(3):473-490

Melander A, Löfving M, Andersson D, Elgh F, Thulin M (2016) Introducing the Hoshin Kanri strategic management system in manufacturing SMEs. Manag Decis 54(10):2507-2523

Nicholas J (2016) Hoshin kanri and critical success factors in quality management and lean production. Total Qual Manag Bus Excell 27(3-4):250-264

Nonaka I (1994) A dynamic theory of organizational knowledge creation. Organ Sci 5(1):14-37

Oliver AM, Montgomery K, Barda S (2019) The multi-level process of trust and learning in universityindustry innovation collaborations. J Technol Transf Feb 28:1-22

Osborn AF (1953) Applied Imagination: Principles and Procedures of Creative Thinking. Charles Scribner's Sons, New York

Paterson TA, Harms PD, Tuggle CS (2018) Revisiting the rigor-relevance relationship: An institutional logics perspective. Hum Resour Manag 57(6):1371-1383

Pearce WB, Pearce KA (2004) Taking a communication perspective on dialogue. In: Anderson R, Baxter LA, Cissna KN (eds) Dialogue: Theorizing difference in communication studies. SAGE Publications, Thousand Oaks, pp 39-56

Pertuze JA, Calder ES, Greitzer EM, Lucas WA (2010) Best practices for industry-university collaboration. MIT Sloan Manag Rev 51(4):83

Polanyi M (1966) The Tacit Dimension. Doubleday \& Co, Garden City, NY

Poppo L (2013) 6. Origins of inter-organizational trust: a review and query for further research. In: Bachmann R, Zaheer A (eds) Handbook of Advances in Trust Research. Edward Elgar Publishing 
Raelin JA (2012) The manager as facilitator of dialogue. Organization 20(6):818-839

Romme AGL, Avenier MJ, Denyer D, Hodgkinson GP, Pandza K, Starkey K, Worren N (2015) Towards common ground and trading zones in management research and practice. Br J Manag 26(3):544-559

Rousseau DM, Sitkin SB, Burt RS, Camerer C (1998) Not so different after all: A cross-discipline view of trust. Acad Manage Rev 23(3):393-404

Rutten W, Blaas-Franken J, Martin H (2016) “The impact of (low) trust on knowledge sharing”. J Knowl Manag 20(20):199-214

Rynes SL, Bartunek JM, Daft RL (2001) Across the great divide: Knowledge creation and transfer between practitioners and academics. Acad Manag J 44(2):340-355

Sako M (1992) Price, quality and trust: Inter-firm relations in Britain and Japan, vol 18. Cambridge University Press

Santoro MD, Saparito PA (2003) The firm's trust in its university partner as a key mediator in advancing knowledge and new technologies. IEEE Trans Eng Manage 50(3):362-373

Scolari L, Coghlan D, Shani AB (2015) Sense making in collaborative management research: Insights from an Italian social cooperative. Res Organ Chang Dev 23:167-194

Schutz A, Luckmann T (1973) The structures of the life-world, vol 1. Northwestern university press

Seppänen R, Blomqvist K, Sundqvist S (2007) Measuring inter-organizational trust-a critical review of the empirical research in 1990-2003. Ind Mark Manage 36(2):249-265

Shani AB, Tenkasi RV, Alexander BN (2017) Knowledge and practice: A historical perspective on collaborative management research. In: Bartunek J, McKenzie J (eds) Academic practitioner research partnership: Developments, complexities and opportunities. Routledge Publications, London

Sharma G, Bansal P (2020) Cocreating rigorous and relevant knowledge. Acad Manag J 63(2):386-410

Soulard CT, Lardon S (2019) Action-Research Helps Researchers Foster Smart Rural Development: Two Case Studies on Local Food Policy. Syst Pract Action Res 32(2):155-166

Tennant C, Roberts P (2001) Hoshin Kanri: a tool for strategic policy deployment. Knowl Process Manag $8(4): 262-269$

Thune T (2007) University-industry collaboration: The network embeddedness approach. Sci Public Policy 34(3):158-168

Tootell A, Kyriazis E, Billsberry J, Ambrosini V, Garrett-Jones S, Wallace G (2020) "Knowledge creation in complex inter-organizational arrangements: understanding the barriers and enablers of universityindustry knowledge creation in science-based cooperation". J Knowl Manag 25(4):743-769

Tsoukas H (2009) A dialogical approach to the creation of new knowledge in organizations. Organ Sci 20(6):941-957

Van de Ven AH (2018) Developing Capabilities of Engaged Scholarship. In: Bartunek JM, McKenzie J (eds) Academic-Practitioner Partnerships: Developments, Complexities, Opportunities. Routledge, London, pp 107-1025

Vangen S, Huxham C (2003) Nurturing collaborative relations: Building trust in interorganizational collaboration. J Appl Behav Sci 39(1):5-31

Vanneste BS, Puranam P, Kretschmer T (2014) Trust over time in exchange relationships: Meta-analysis and theory. Strateg Manag J 35(12):1891-1902

Walton D, Krabbe EC (1995) Commitment in dialogue: Basic concepts of interpersonal reasoning. SUNY press

Von Brocke J, Lippe S (2015) Managing collaborative research projects: A synthesis of project management literature and directives for future research. Int J Project Manage 33(5):1022-1039

Yang S-U, Kang M, Cha H (2015) A study of dialogic communication, trust and distrust: Testing a scale for measuring organization-public dialogic communication (OPDC). J Public Relat Res 27:175-192

Publisher's Note Springer Nature remains neutral with regard to jurisdictional claims in published maps and institutional affiliations. 